Article

\title{
Assessing the Flexural Properties of Epoxy Composites with Extremely Low Addition of Cellulose Nanofiber Content
}

\author{
Yingmei Xie, Hiroki Kurita ${ }^{\circledR}$, Ryugo Ishigami and Fumio Narita *®D \\ Department of Materials Processing, Graduate School of Engineering, Tohoku University, Sendai 980-8579, \\ Japan; xie.yingmei.t4@dc.tohoku.ac.jp (Y.X.); kurita@material.tohoku.ac.jp (H.K.); \\ ryugo.ishigami.q7@dc.tohoku.ac.jp (R.I.) \\ * Correspondence: narita@material.tohoku.ac.jp
}

Received: 12 December 2019; Accepted: 7 February 2020; Published: 9 February 2020

\begin{abstract}
Epoxy resins are a widely used common polymer due to their excellent mechanical properties. On the other hand, cellulose nanofiber (CNF) is one of the new generation of fibers, and recent test results show that CNF reinforced polymers have high mechanical properties. It has also been reported that an extremely low $\mathrm{CNF}$ addition increases the mechanical properties of the matrix resin. In this study, we prepared extremely-low CNF ( 1 wt.\%) reinforced epoxy resin matrix (epoxy-CNF) composites, and tried to understand the strengthening mechanism of the epoxy-CNF composite through the three-point flexural test, finite element analysis (FEA), and discussion based on organic chemistry. The flexural modulus and strength were significantly increased by the extremely low CNF addition (less than $0.2 \mathrm{wt} . \%$ ), although the theories for short-fiber-reinforced composites cannot explain the strengthening mechanism of the epoxy-CNF composite. Hence, we propose the possibility that CNF behaves as an auxiliary agent to enhance the structure of the epoxy molecule, and not as a reinforcing fiber in the epoxy resin matrix.
\end{abstract}

Keywords: flexural test; finite element method; cellulose nanofiber; epoxy resin

\section{Introduction}

Epoxy resins are widely used in adhesives, coatings, electronics, sporting goods, and aerospace applications, owing to their excellent properties of being a polymeric material with high strength, stiffness, temperature resistance, dimensional stability, and fatigue resistance [1]. Cellulose nanofiber (CNF) is a large aspect ratio, string-like, sustainable material, which is highly crystalline and consists of transversely-filled long cellulose molecules linked by strong hydrogen bonds. It is well-known that the long cellulose molecules are incorporated into the cell walls of higher plants, such as hemicellulose and lignin [2,3]. In order to fully capitalize on the intensified properties of doped nano-particles, one of the most critical things is that they should have a homogeneous dispersion in the polymeric matrix. Different dispersion methods have been considered, including the use of the dilution method, ultrasonication, high shear mixing, the addition of a chemical surfactant, and so on [4-9].

To avoid CNF agglomeration, nanofiber networks are prepared by filtration from a dilute CNF water suspension. The process involves solvent exchange with acetone, and the ultrafiltration of fiber slurries using a Millipore ultrafiltration apparatus, with membranes to preserve the structure of the individual nanofibers. Lu et al. dispersed modified CNF using silane and titanate coupling agents in acetone and reported an increase of storage modulus from 2.59 to $3.45 \mathrm{GPa}$ at $30^{\circ} \mathrm{C}$, with a nanocellulose content of $5 \mathrm{wt} . \%$ [4]. Omrani et al. discussed the effects of cellulose on the curing behavior and properties and suggested that a nanocellulose content of $0.5 \mathrm{phr}$ (per hundred resin) 
is the optimum content [5]. Tang and Weder dispersed cellulose whiskers in dimethylformamide (DMF) by either freeze-drying, or solvent exchange procedures, to avoid using coupling agents [6]. They reported that the Young's modulus of the epoxy resin with 20 vol. \% of tunicate whiskers was $5.7 \mathrm{GPa}$, while that of the neat epoxy resin was 1.6 GPa. Shibata and Nakai mixed water-soluble components with microfibrillated cellulose, followed by suspension freeze-drying and curing processes at elevated temperature [7]. They reported that the Young's modulus and the tensile strength of the epoxy resin were increased from 1.7 to $2.6 \mathrm{GPa}$, and from $60 \mathrm{MPa}$ to approximately $80 \mathrm{MPa}$, respectively. As mentioned above, there are several studies of CNF reinforced polymer composite materials with higher CNF weight fractions (1 wt.\% ).

On the other hand, Zhang et al. fabricated CNF and polysulfone (PSF) modified epoxy nanocomposites using a combination of solvent exchange and melt blending [8]. They reported that a CNF addition of $0.2 \mathrm{wt} . \%$ increased the impact strength by $\sim 49 \%$. Kurita et al. also reported that the insertion of epoxy resin with $0.1 \mathrm{wt} . \%$ CNF layers increased the flexural strength of glass fiber reinforced plastic (GFRP) composite laminates by $125 \%$, whereas the flexural modulus of the CNF layer inserted GFRP laminates was constant [9]. Therefore, they concluded that a slight CNF addition $(\sim 1 \mathrm{vol} . \%)$ can increase the mechanical properties of the resin matrix.

In this study, we prepared extremely-low CNF ( 0.44 vol.\%) reinforced epoxy resin matrix (epoxy-CNF) composites via high shear mixing. After that, we evaluated and analyzed the flexural properties of the epoxy-CNF composites by the three-point flexural test and finite element method, respectively. Moreover, we discussed the strengthening mechanism of epoxy-CNF composites, based on organic chemistry.

\section{Experimental Procedure}

Figure 1 shows the specimen preparation process. We prepared Bisphenol $\mathrm{F}$ epoxy resin (di-epoxide terminated molecule), Amine curing agent (Diethylenetriamine, ST 12), and CNF 2 wt.\% slurry (BiNFi-s, IMa-10002, Sugino machine Limited). These three solutions were mixed by a mechanical mixer and stirred twice, both before and after adding the curing agent, for 10 and $14 \mathrm{~min}$, respectively. The rotation speed was $400 \mathrm{r} / \mathrm{min}$ or $2000 \mathrm{r} / \mathrm{min}$. The volume fraction of CNF was controlled between 0 and $0.44 \mathrm{vol} . \%$ in the final epoxy-CNF composite. Afterwards, the solution was cured at $80^{\circ} \mathrm{C}$ for $3 \mathrm{~h}$. The cured specimens were cut to $40 \times 10 \times 2 \mathrm{~mm}^{3}$ and polished for a three-point bending test.

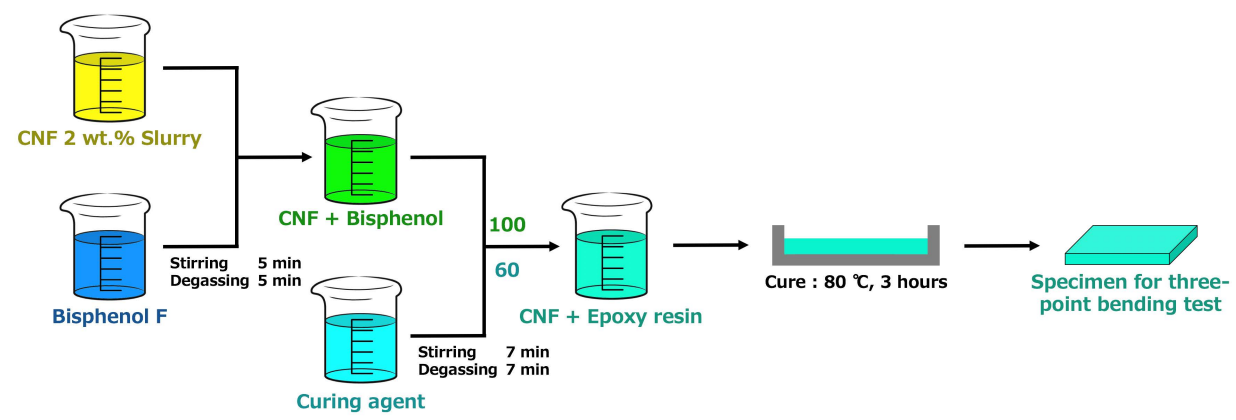

Figure 1. Schematic illustration of the specimen preparation process.

The flexural tests were performed according to the standard test method JIS K 7017 [10] under a three-point bend configuration, as shown in Figure 2. A load $P$ was applied directly at the center of the specimen. In this study, loading nose and support roller diameters were $R=10$ and $5 \mathrm{~mm}$, respectively. The support span length was chosen to be $s=30 \mathrm{~mm}$. We conducted flexural tests using an Autograph (SHIMAZU AG-50kNXD) with a $5 \mathrm{kN}$ load cell at a displacement rate of $1 \mathrm{~mm} / \mathrm{min}$. We carried out five replications for each test. 


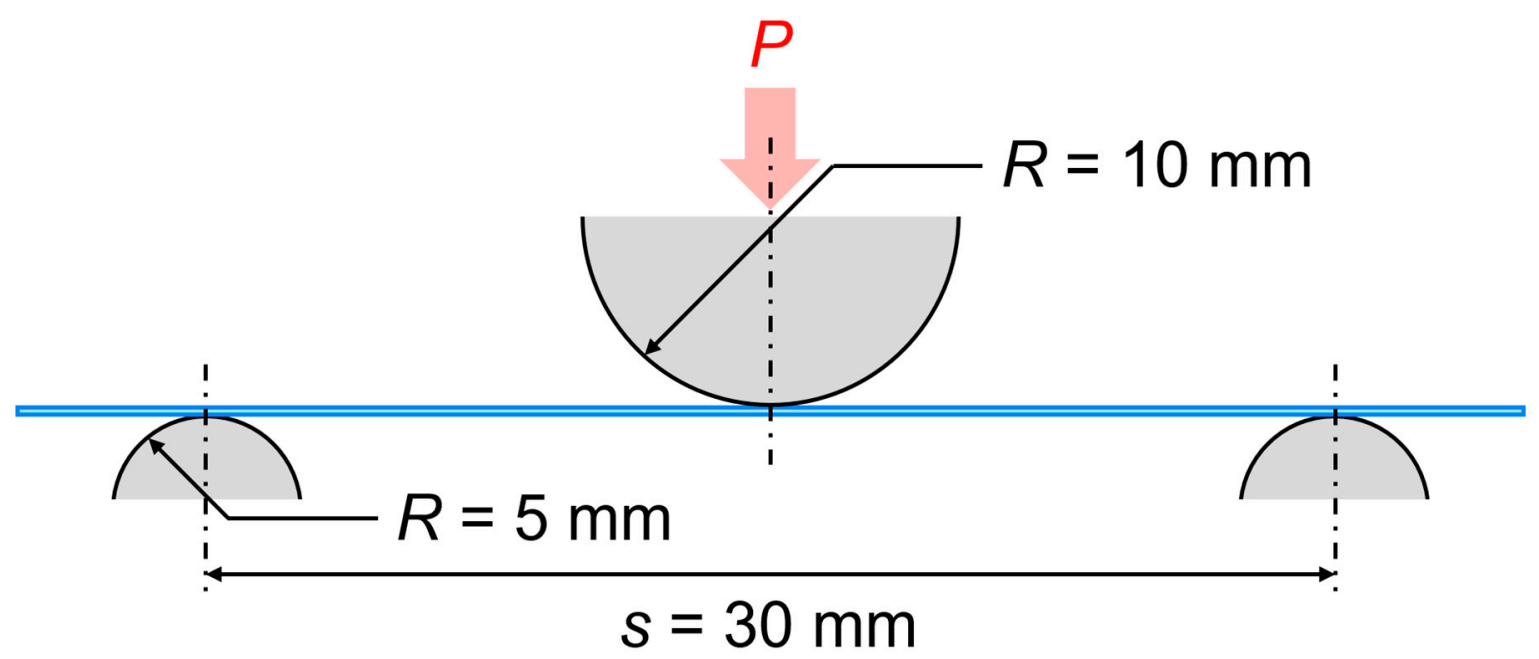

Figure 2. Schematic illustration of a three-point flexural test.

The flexural stress $\left(\sigma_{\mathrm{f}}\right)$, flexural strain $\left(\varepsilon_{\mathrm{f}}\right)$, and flexural modulus $\left(E_{\mathrm{f}}^{\mathrm{c}}\right)$ of the composite were estimated by the following equations:

$$
\begin{gathered}
\sigma_{\mathrm{f}}=\frac{3 P s}{2 b h^{2}} \\
\varepsilon_{\mathrm{f}}=\frac{6 \delta h}{s^{2}} \\
E_{\mathrm{f}}^{\mathrm{c}}=\frac{s^{3}}{4 b h^{3}} \frac{P^{\prime \prime}-P^{\prime}}{\delta^{\prime \prime}-\delta^{\prime}}
\end{gathered}
$$

where $l=40 \mathrm{~mm}, b=10 \mathrm{~mm}, h=2 \mathrm{~mm}$ are the length, width, and thickness of the specimen, $\delta$ is the deflection of the load point and the superscript $\mathrm{c}$ denotes the composite, respectively. To determine the flexural modulus, the deflections $\delta^{\prime}$ and $\delta^{\prime \prime}$, corresponding to the given values of the flexural strain, $\varepsilon_{f}^{\prime}=0.0005$ and $\varepsilon_{f}^{\prime \prime}=0.0025$, were obtained, respectively, using the following equations:

$$
\begin{aligned}
\delta^{\prime} & =\frac{\varepsilon_{\mathrm{f}} s^{2}}{6 h} \\
\delta^{\prime \prime} & =\frac{\varepsilon_{\mathrm{f}}^{\prime \prime} s^{2}}{6 h}
\end{aligned}
$$

In Equation (3), $P^{\prime}$ and $P^{\prime \prime}$ are the loads corresponding to the deflections $\delta^{\prime}$ and $\delta^{\prime \prime}$, respectively.

\section{Finite Element Analysis}

We estimated the flexural modulus of epoxy-CNF composites using the software, ANSYS Multiphysics code (ver. 11.0). The friction between specimen and jigs was not considered in this study. The epoxy-CNF composites were considered as one homogeneous isotropic elastic material. Let us now consider the Cartesian coordinate system $\mathrm{O}-x y z$. The constitutive relations can be written as follows:

$$
\left\{\begin{array}{c}
\varepsilon_{x x} \\
\varepsilon_{y y} \\
\varepsilon_{z z} \\
2 \varepsilon_{y z} \\
2 \varepsilon_{z x} \\
2 \varepsilon_{x y}
\end{array}\right\}=\left[\begin{array}{cccccc}
1 / E^{c} & -v^{c} / E^{c} & -v^{c} / E^{c} & 0 & 0 & 0 \\
-v^{c} / E^{c} & 1 / E^{c} & -v^{c} / E^{c} & 0 & 0 & 0 \\
-v^{c} / E^{c} & -v^{c} / E^{c} & 1 / E^{c} & 0 & 0 & 0 \\
0 & 0 & 0 & 1 / G^{c} & 0 & 0 \\
0 & 0 & 0 & 0 & 1 / G^{c} & 0 \\
0 & 0 & 0 & 0 & 0 & 1 / G^{c}
\end{array}\right]\left\{\begin{array}{c}
\sigma_{x x} \\
\sigma_{y y} \\
\sigma_{z z} \\
\sigma_{y z} \\
\sigma_{z x} \\
\sigma_{x y}
\end{array}\right\}
$$


where $\varepsilon_{x x}, \varepsilon_{y y}, \varepsilon_{z z}, \varepsilon_{y z}, \varepsilon_{z x}, \varepsilon_{x y}$ are the strain components, $\sigma_{x x}, \sigma_{y y}, \sigma_{z z}, \sigma_{y z}, \sigma_{z x}, \sigma_{x y}$ are the stress components, $E^{\mathrm{C}}$ is the Young's modulus, $v^{\mathrm{C}}$ is the Poisson's ratio and $G^{\mathrm{C}}$ is the shear modulus, respectively. The shear modulus $G^{c}$ is related to Young's modulus and Poisson's ratio by the following equation:

$$
G^{\mathrm{c}}=\frac{E^{\mathrm{c}}}{2\left(1+v^{\mathrm{c}}\right)}
$$

The elastic properties of the epoxy-CNF composites were determined by the theoretical Halpin-Tsai model for short-fiber-reinforced composite materials [11,12]. The model includes parameters, such as volume fraction $\left(V^{\mathrm{f}}\right)$, length $\left(l^{\mathrm{f}}\right)$, and diameter $\left(d^{\mathrm{f}}\right)$ of the CNF. The superscript $\mathrm{f}$ refers to the CNF. The Young's modulus of the epoxy-CNF composites is given by

$$
E^{\mathrm{c}}=\frac{3}{8} E_{11}+\frac{5}{8} E_{22}
$$

and

$$
\begin{aligned}
& E_{11}=\frac{1+2 \xi \eta_{\mathrm{L}} V^{\mathrm{f}}}{1-\eta_{\mathrm{L}} V^{\mathrm{f}}} E^{\mathrm{m}} \\
& E_{22}=\frac{1+2 \eta_{\mathrm{T}} V^{\mathrm{f}}}{1-\eta_{\mathrm{T}} V^{\mathrm{f}}} E^{\mathrm{m}}
\end{aligned}
$$

where $E^{\mathrm{m}}$ is the Young's modulus of the matrix (obtained from the flexural test), the superscript $\mathrm{m}$ represents the matrix, and $\eta_{\mathrm{L}}, \eta_{\mathrm{T}}$ and $\xi$ can be expressed as

$$
\begin{gathered}
\eta_{\mathrm{L}}=\frac{\frac{E^{\mathrm{f}}}{E^{\mathrm{m}}}-1}{\frac{E^{\mathrm{f}}}{E^{\mathrm{m}}}+2 \xi} \\
\eta_{\mathrm{T}}=\frac{\frac{E^{\mathrm{f}}}{E^{\mathrm{m}}}-1}{\frac{E^{\mathrm{f}}}{E^{\mathrm{m}}}+2} \\
\xi=\frac{l^{\mathrm{f}}}{d^{\mathrm{f}}}
\end{gathered}
$$

Here, $\xi$ is a shape parameter depending on the geometry and aspect ratio of the reinforcement. Considering the specific long-length and short-length CNFs used, their length $\left(l^{\mathrm{f}}\right)$, their diameter $\left(d^{\mathrm{f}}\right)$, and Young's modulus $\left(E^{\mathrm{f}}\right)$ of the CNF were taken to be $5000 \mathrm{~nm}, 10 \mathrm{~nm}$, and $145 \mathrm{GPa}$, respectively, according to the product information supplied by Sugino machine Limited. The model of the CNF dimensions neglects the effect of compounding on the CNF morphology (e.g., possible influence of shearing stresses experienced during preparation). In reality, this is not true, but the assumption does not affect the macroscopic behavior of the epoxy-CNF composites.

The finite element model of the flexural tests was developed as shown in Figure 3. Total nodes were 6480 (specimen: 1200, jigs: 5280). In this model, the Cartesian coordinate system was used with the $x-, y$-, and $z$-axes in the directions of length, width, and thickness, respectively. The model was three-dimensional and treated the entire test specimen as one homogeneous material with isotropic elastic moduli, $E^{\mathrm{c}}, v^{\mathrm{c}}$, and $G^{\mathrm{c}}$, as given by Equations (7) and (8). Note that Poisson's ratio of the epoxy-CNF composites was assumed to be $v^{\mathrm{c}}=v^{\mathrm{m}}=0.25$ in the finite element analysis (FEA). The dimensions correspond to those of the specimens. Eight-node brick elements were used for meshing the specimens. Owing to symmetry, a quadrant of the specimen $(0 \leq x \leq l / 2,0 \leq y \leq b / 2$, $0 \leq z \leq h)$ was analyzed. The displacement boundary conditions of the specimen are shown as follows:

$$
u_{x}(0, y, z)=0\left(0 \leq y \leq \frac{b}{2}, 0 \leq z \leq h\right)
$$




$$
\begin{gathered}
u_{y}(x, 0, z)=0\left(0 \leq x \leq \frac{l}{2}, 0 \leq z \leq h\right) \\
u_{z}\left(\frac{s}{2}, y, h\right)=0\left(0 \leq y \leq \frac{b}{2}\right)
\end{gathered}
$$

where $u_{x}(x, y, z), u_{y}(x, y, z)$, and $u_{z}(x, y, z)$ are the displacement components. Contact elements were used for the contact region between the test fixture and the specimen. The coefficient of friction for the contact surfaces was assumed to be zero. The specimen was loaded by prescribed displacement $\delta_{0}$ in the $z$-direction on the top surface of the loading nose. The total nodal force on the top surface of the loading nose was quadrupled (on account of the plane of symmetry). The calculated load $P_{0}$ corresponds to the load measured by a load cell in the experiments.

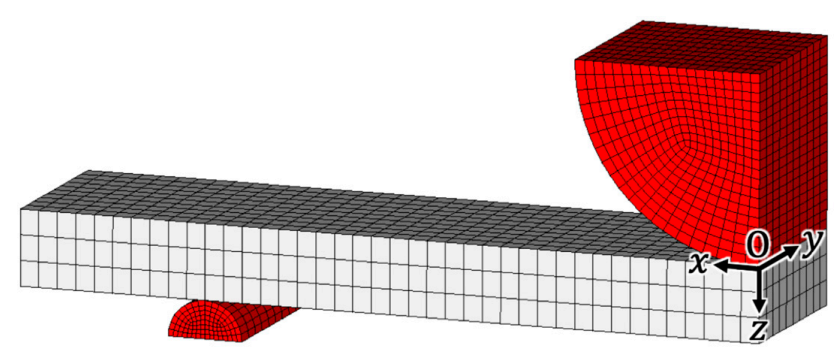

Figure 3. Finite element analysis model of a three-point flexural test.

\section{Results and Discussion}

Figure 4 shows the typical flexural stress-strain curves of the neat epoxy and epoxy-CNF composites. The tendency was that the flexural modulus and strength of the epoxy resin were increased by a CNF addition, while the fracture elongation of the epoxy resin decreased with CNF addition. It is noticeable that the flexural modulus and strength were significantly increased by an extremely low CNF addition (less than 0.145 vol.\%) as shown in Figure 5. Furthermore, the flexural modulus of the epoxy-CNF composites increased linearly, up to $0.145 \mathrm{vol} \%$ (except for the epoxy-CNF 0.022 vol.\% composite). The red line in Figure $5 \mathrm{a}$ is the theoretical flexural modulus of the epoxy-CNF composites estimated by FEA. The experimental flexural modulus of the epoxy-CNF composites was higher than the theoretical one, i.e., this result indicates that the flexural modulus of the epoxy-CNF composites should not be discussed as short-fiber-reinforced composites, although it seems that the flexural modulus of the epoxy-CNF composites, with a CNF of more than approximately $0.32 \mathrm{vol} . \%$, is apparently compliant with the model of short-fiber-reinforced composites. However, there is currently no analysis method to explain the strengthening mechanism of the epoxy-CNF composites with an extremely low CNF addition.

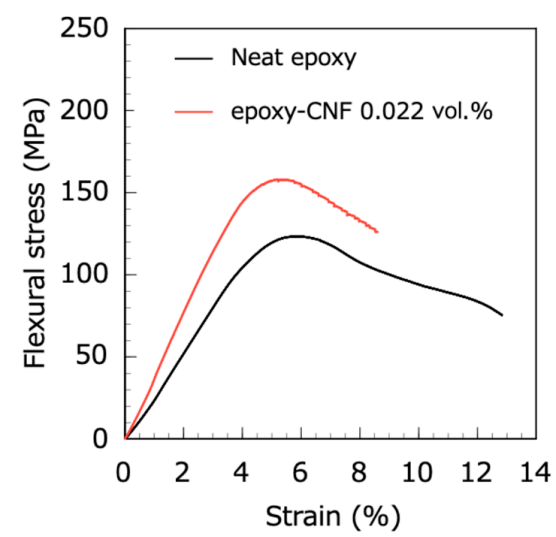

Figure 4. Flexural stress-strain curves of neat epoxy and epoxy-CNF 0.022 vol.\% composite. 

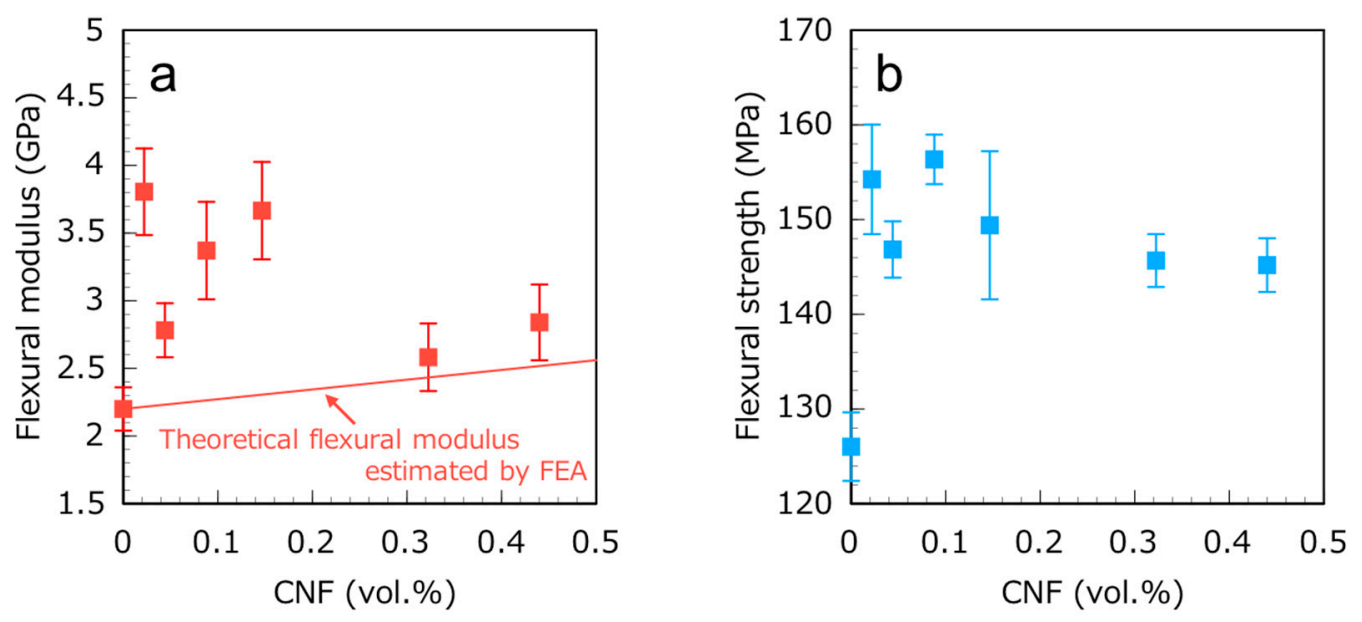

Figure 5. (a) Flexural modulus and (b) flexural strength of epoxy-CNF composites.

Nevertheless, we deduce two strengthening mechanisms of the epoxy-CNF composite from the point of view of organic chemistry. Firstly, in view of the fact that the amine curing agent that was used, diethylenetriamine, contains mass $\mathrm{NH}_{2}$ groups, we suggest the strengthening mechanism of the epoxy-CNF composite occurs via the chemical reaction between the CNF and active amide (amino $\mathrm{CNF}$ ). Guan et al. demonstrated that hydroxyl- and amino-functionalized boron nitride nanotubes, with epoxy nanocomposites, improve the strength due to the interaction of surface functional $\mathrm{OH} / \mathrm{NH}_{2}$ groups and/or covalent connections with epoxide rings [13]. Similarly, by using Fourier Transform Infrared Spectroscopy (FT-IR), Vijayan et al. reported that active amide groups were formed by the chemical reaction between amine curing agents and $\mathrm{CNF}$, leaving some unreacted amine groups [14]. The presence of carboxyl groups on the CNF was confirmed by the presence of the stretching vibration of $\mathrm{C}=\mathrm{O}$ at $1730 \mathrm{~cm}^{-1}$ [15]. For amine immobilized cellulose nanofibers and diethylenetriamine curing agent (AiCNF), Hubbe et al. observed new peaks at $1560 \mathrm{~cm}^{-1}$ and $1640 \mathrm{~cm}^{-1}$, showing the formation of amides as a result of the reaction between $\mathrm{C}=\mathrm{O}$ in the $\mathrm{CNF}$ with amine, and also suggested a chemical reaction theory (see Figure 6) [16]. Furthermore, the general reaction mechanism between a carboxylic acid and an amine is shown in Figure 7 [17]. At a high temperature, amide groups can be formed from the ammonium carboxylate salt due to the driving off or consumption of the water. Therefore, the surface of the CNF molecule with the rich carboxylic acid groups has the potential to react with amine functions, thereby forming amide linkages [18]. 

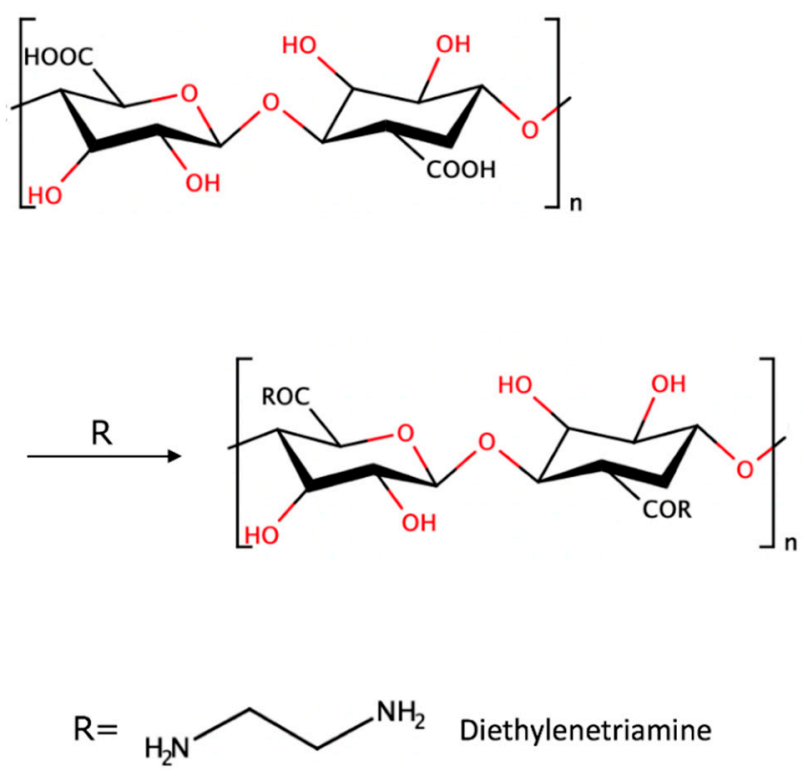

Figure 6. 2,2,6,6-tetramethyl-1-piperidinyloxy (TEMPO)-mediated oxidation of crystals and amino functionalization of the oxidized materials (amino-f-cellulose).<smiles>[R]C(=O)O</smiles>

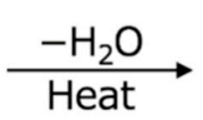<smiles>[R]C(=O)NCCN</smiles>

Figure 7. General reaction mechanism between a carboxylic acid and an amine.

The mechanical properties of epoxy resin depend on the curing conditions $[19,20]$. It means that the epoxide molecules contributing to the curing reaction react with themselves, and/or with other reactive molecules, to form a cross-linked network, whether or not a catalyst is used. Figure 8 shows the chemical reaction during amine curing of epoxy resin [21]. Besides the primary amine-epoxy additions, the other two major reactions involved in amine curing of epoxy resins are secondary amine-epoxy, and secondary amine-epoxy and hydroxyl-epoxy additions. The latter reaction only becomes more effective after an adequate increase of the $-\mathrm{OH}$ group concentration due to the influence of the two former reactions [22]. Therefore, it is likely that this reaction occurs inside the epoxy-CNF composite, in consideration of the high mass of exposed hydrogen groups on the CNF surface, as well as the $98 \%$ of water involved in the CNF gel. Zhang et al. and Ansari et al. have implied that the hydroxyl groups on the CNF surfaces accelerated the curing reaction [23,24]. Figure 9 shows the acceleration mechanism for the epoxy-diamine reaction with CNF. It seems that this reaction is promoted by the formation of a trimolecular transition state $[25,26]$. 


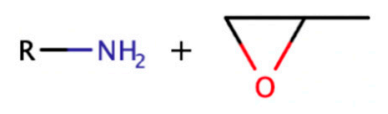

Primary Epoxy resin hardener

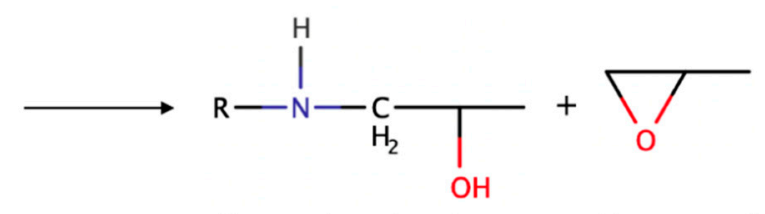

Secondary hardener Epoxy resin

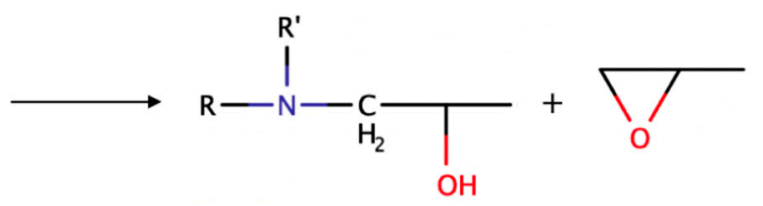

Tertiary hardener Epoxy resin

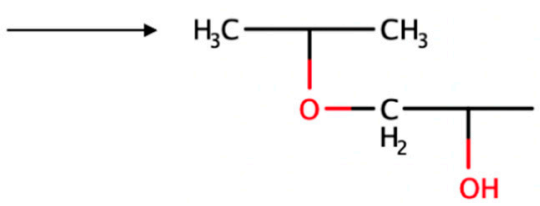

Figure 8. Chemical reaction during amine curing of epoxy resin.

\section{Epoxy monomer}
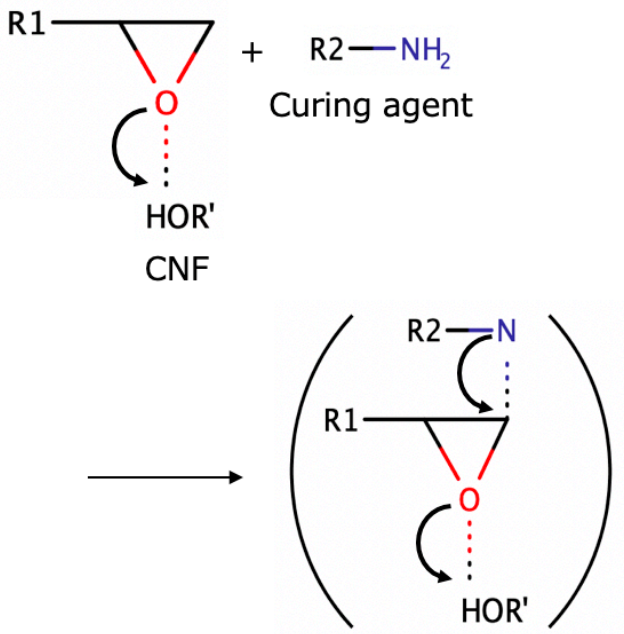

Trimolecular transition state

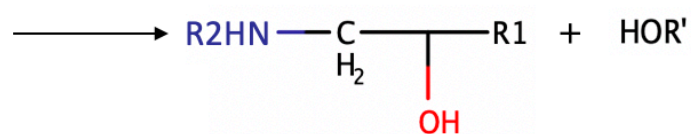

Figure 9. Acceleration mechanism for the epoxy-diamine reaction with CNF.

Secondly, the carboxyl group participates in the opening of the epoxide rings, resulting in an ester bond and the formation of an $-\mathrm{OH}$ group [26]. Figure 10 shows the chemical reaction between carboxylated carbon nanotubes (CNT) and di-epoxide ringsis [20]. Both the CNF and 
CNT are nano-scale materials. Thus, it seems that their nano properties are similar. Furthermore, the carboxylated $\mathrm{CNT}$ has $-\mathrm{COOH}$ groups on its surface, similar to the $\mathrm{CNF}$ having $-\mathrm{COOH}$ groups on its surface. Hence, it is implied that $\mathrm{CNF}$ can react with the di-epoxide ringsis.

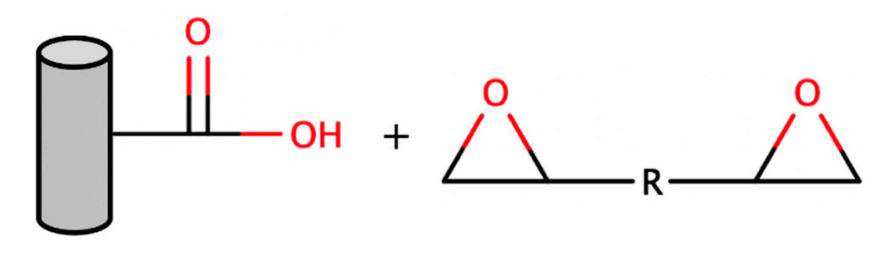

\section{Carboxylated CNT Di-epoxide molecule}

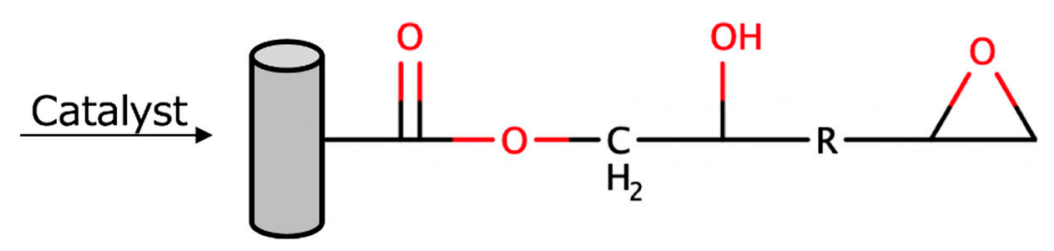

Figure 10. Chemical reaction between carboxylated carbon nanotubes (CNT) and di-epoxide ringsis.

\section{Conclusions}

Epoxy-CNF composites were prepared with an extremely-low CNF ( 0.44 vol.\%) via a high shear mixing. The flexural modulus and strength were significantly increased by an extremely low CNF addition (less than 0.145 vol.\%). However, the outstanding flexural modulus of epoxy-CNF composites was higher than the theoretical one estimated by FEA, i.e., it was implied that the theories for short-fiber-reinforced composites are not suitable to discuss the flexural properties of epoxy-CNF composites. It seems that the flexural properties of epoxy-CNF composites were increased by the chemical reaction between epoxy resin and CNF.

Author Contributions: Y.X. prepared the samples and performed the experiments. Y.X. and H.K. analyzed the data and wrote the paper. R.I. conducted the finite element analysis. F.N. conceived the research and edited the paper. All authors have read and agreed to the published version of the manuscript.

Funding: This research received no external funding.

Conflicts of Interest: The authors declare no conflict of interest.

\section{References}

1. Nair, S.S.; Kuo, P.Y.; Chen, H.; Yan, N. Investigating the effect of lignin on the mechanical, thermal, and barrier properties of cellulose nanofibril reinforced epoxy composite. Ind. Crops Prod. 2017, 100, $208-217$. [CrossRef]

2. Henriksson, M.; Henriksson, G.; Berglund, L.; Lindstrom, T. An environmentally friendly method for enzyme-assisted preparation of microfibrillated cellulose (MFC) nanofibers. Eur. Polym. J. 2007, 43, 3434-3441. [CrossRef]

3. Nogi, M.; Iwamoto, S.; Nakagaito, A.; Yano, A. Optically transparent nanofiber paper. Adv. Mater. 2009, 21, 1595-1598. [CrossRef]

4. Lu, J.; Askeland, P.; Drzal, L.T. Surface modification of microfibrillated cellulose for epoxy composite applications. Polymer 2008, 49, 1285-1296. [CrossRef]

5. Omrani, A.; Simon, L.C.; Rostami, A.A. Influences of cellulose nanofiber on the epoxy network formation. Mater. Sci. Eng. A 2008, 490, 131-137. [CrossRef]

6. Tang, L.; Weder, C. Cellulose whisker/epoxy resin nanocomposites. ACS Appl. Mater. Interfaces 2010, 2, 1073-1080. [CrossRef] 
7. Shibata, M.; Nakai, K. Preparation and properties of biocomposites composed of bio-based epoxy resin, tannic acid, and microfibrillated cellulose. J. Polym. Sci. Part B 2010, 48, 425-433. [CrossRef]

8. Zhang, Y.; Song, P.; Fu, S.; Chen, F. Morphological structure and mechanical properties of epoxy/polysulfone/cellulose nanofiber ternary nanocomposites. Compos. Sci. Technol. 2015, 115, 66-71. [CrossRef]

9. Kurita, H.; Xie, Y.; Katabira, K.; Honda, R.; Narita, F. The insert effect of cellulose nanofiber layer on glass fiber-reinforced plastic laminates and their flexural properties. Mater. Des. Process. Commun. 2019, 1, e58. [CrossRef]

10. JIS K 7017. Fiber-Reinforced Plastics Composites-Determination of Flexural Properties; Japanese Industrial Standards: Tokyo, Japan, 1999.

11. Halpin, J.C. Stiffness and expansion estimates for oriented short fiber composites. J. Compos. Mater. 1969, 3, 732-734. [CrossRef]

12. Halpin, J.C.; Kardos, J.L. The Halpin-Tsai equations: A review. Polym. Eng. Sci. 1976, 16, 344-352.

13. Guan, J.; Ashrafi, B.; Martinez-Rubi, Y.; Jakubinek, M.B.; Rahmat, M.; Kim, K.S.; Simard, B. Epoxy resin nanocomposites with hydroxyl $(\mathrm{OH})$ and amino $\left(\mathrm{NH}_{2}\right)$ functionalized boron nitride nanotubes. Nanocomposites 2018, 4, 10-17. [CrossRef]

14. Vijayan, P.; Tanvira, A.; El-Gawadya, Y.H.; Al-Maadeed, M. Cellulose nanofibers to assist the release of healing agents in epoxy coatings. Prog. Org. Coat. 2017, 112, 127-132. [CrossRef]

15. Leung, A.C.W.; Hrapovic, S.; Lam, E.; Liu, Y.; Male, K.B.; Mahmoud, K.A.; Luong, J.H.T. Characteristics and properties of carboxylated cellulose nanocrystals prepared from a novel one-step procedure. Small 2011, 7, 302-305. [CrossRef]

16. Hubbe, M.A.; Rojas, O.J.; Lucia, L.A. Green modification of surface characteristics of cellulosic materials at the molecular or nano scale: A review. Bioresources 2015, 10, 6095-6206. [CrossRef]

17. Zhang, J.; Xu, Y.C.; Huang, P. Effect of cure cycle on curing process and hardness for epoxy resin. Express Polym. Lett. 2009, 3, 534-541. [CrossRef]

18. Shechter, L.; Wynstra, J. Glycidyl ether reactions with alcohols, phenols, carboxylic acids, and acid anhydrides. Ind. Eng. Chem. 1956, 48, 86-93. [CrossRef]

19. Day, R.J.; Lovell, P.A.; Wazzan, A.A. Toughened carbon/epoxy composites made by using core/shell particles. Compos. Sci. Technol. 2001, 61, 41-56. [CrossRef]

20. Saeb, M.R.; Bakhshandeh, E.; Khonakdar, H.A.; Mäder, E.; Scheffler, C.; Heinrich, G. Cure kinetics of epoxy nanocomposites affected by MWCNTs functionalization: A review. Sci. World J. 2013, 2013, 703708. [CrossRef]

21. Kono, H. Characterization and properties of carboxymethyl cellulose hydrogels crosslinked by polyethylene glycol. Carbohydr. Polym. 2014, 106, 84-93. [CrossRef]

22. Acocella, M.A.; Corcione, C.E.; Giuri, A.; Maggio, M.; Maffezzoli, A.; Guerra, G. Graphene oxide as a catalyst for ring opening reactions in amine crosslinking of epoxy resins. RSC Adv. 2016, 28, 23858-23865. [CrossRef]

23. Zhang, Y.; Ling, Q.; Lu, X.; Fang, Q.; Sun, F. Rheology, morphological evolution, thermal, and mechanical properties of epoxy modified with polysulfone and cellulose nanofibers. J. Appl. Polym. Sci. 2019, 137, 48628. [CrossRef]

24. Ansari, F.; Galland, S.; Johansson, M.; Plummer, C.J.G.; Berglund, L.A. Cellulose nanofiber network for moisture stable, strong and ductile biocomposites and increased epoxy curing rate. Compos. Part A 2014, 63, 35-44. [CrossRef]

25. Smith, I.T. The mechanism of the crosslinking of epoxide resins by amines. Polymer 1961, 2, 95-108. [CrossRef]

26. Tomas, R.; Durix, S.; Sinturel, C.; Omonov, T.; Goossens, S.; Groeninckx, G.; Moldenaers, P.; Thomas, S. Cure kinetics, morphology and miscibility of modified DGEBA-based epoxy resin-Effects of a liquid rubber inclusion. Polymer 2007, 48, 1695-1710. [CrossRef]

(C) 2020 by the authors. Licensee MDPI, Basel, Switzerland. This article is an open access article distributed under the terms and conditions of the Creative Commons Attribution (CC BY) license (http://creativecommons.org/licenses/by/4.0/). 